\title{
What is energy for? Social practice and energy demand
}

Elizabeth Shove and Gordon Walker

DEMAND Centre, FASS Building, Lancaster University, Lancaster, UK, LA1 4YD. e.shove@lancaster.ac.uk; g.p.walker@lancaster.ac.uk

\begin{abstract}
Energy has an ambivalent status in social theory, variously figuring as a driver or an outcome of social and institutional change, or as something that is woven into the fabric of society itself. In this paper we consider the underlying models on which different approaches depend. One common strategy is to view energy as a resource base, the management and organisation of which depends on various intersecting systems: political, economic and technological. This is not the only route to take. In this paper we develop an alternative approach, viewing energy supply and energy demand as part of the ongoing reproduction of bundles and complexes of social practice. In articulating and comparing these two positions we show how social-theoretical commitments influence the ways in which problems like those of reducing carbon emissions are framed and addressed. Whereas theories of practice highlight basic questions about what energy is for, these issues are routinely and perhaps necessarily obscured by those who see energy as an abstract resource that structures or that is structured by a range of interlocking social systems.
\end{abstract}

\section{$1 \quad$ Introduction}

Despite defining energy as the 'ability to do work', natural scientists rarely comment on the kind of work that is thereby enabled or on how this changes. In engineering and material science, as in energy policy, there is a tendency to take the societal 'need' for energy for granted, and to focus on 
methods of meeting demand more efficiently, or in a manner that reduces $\mathrm{CO}_{2}$ emissions (Allwood et al., 2013). In this context, and in so far as they arise at all, questions about the politics of access, provision and supply, and the details of consumption are delegated to other disciplines, including the social sciences.

This relocates but does not resolve questions about how the need for energy arises, or how such needs evolve. Whilst the relation between energy and society has been a central theme across the social sciences (White, 1943; Verbong and Loorbach, 2012; Nye, 1999; Rosa et al., 1988; Moellers and Zachmann, 2012), there are significant differences of approach. Rather than speaking with a single voice, explanations of energy demand reflect and reproduce contrasting theories of society and of social change.

In reviewing some of this literature, we distinguish between two broad schools of thought. We start with approaches in which forms of energy production and use are taken to be either the cause or the consequence of changing political, economic and technical systems. We then consider the place of energy in theoretical accounts that take social practices to be the 'site' of the social. The relation between energy and social practice is not one that has been explored and discussed in quite these terms before. In moving into this territory we suggest that energy supply and demand are realised through artefacts and infrastructures that constitute and that are in turn woven into bundles and complexes of social practice. From this point of view, the relation between energy and society is not defined by external factors and driving forces. Instead, it is best understood as part of the ongoing reproduction and transformation of society itself. Ironically, this brings us back to a definition of energy as 'the ability to do work', but this time with the possibility of drawing on an appropriately sophisticated account of what that 'work' entails and how it changes.

Deliberate efforts to reduce energy demand necessarily rest on one or another social theoretical account of energy, society and social change. Energy policies consequently foreground and marginalise different lines of enquiry and intervention. In bringing this article to a close we argue 
that dominant approaches sideline basic questions about what energy is for. We conclude with a discussion of how these questions might be brought back into view, and of the policy implications of focusing on the dynamics of social practice and hence on the "work" that energy enables us to do.

\section{$2 \quad$ Energy and social systems}

Sociological interest in resources has arguably waned in recent years, but there is an established tradition that focuses quite explicitly on energy-society relations. In their excellent review of this field, Rosa et al. (1988) explain that early interest in the topic was inspired by thoroughly linear and typically deterministic narratives of societal progress. White's influential article on 'Energy and the Evolution of Culture' takes just such an approach, attributing 'vast social changes' to methods and techniques of energy conversion (Rosa et al., 1988: 153). White's discussion is organised around a series of law-like statements including the suggestion that 'culture develops when the amount of energy harnessed by man per capita per year is increased; or as the efficiency of the technological means of putting this energy to work is increased; or, as both factors are simultaneously increased.' (White, 1943: 338). As White recognises, this equation is sometimes complicated by confounding factors. For instance forms of social and cultural organisation can, on occasion, block technological innovation. In White's words, 'A social system may foster the effective operation of its underlying technology or it may tend to restrain and thwart it.' (White, 1943: 347). Whether this occurs or not, White's basic position is clear: in his analysis the appropriation and use of energy features as a, if not the critical factor determining the rate of societal progress.

White's writing now has a decidedly dated feel, but more recent exercises in modelling energy flows and patterns of resource intensity are founded upon strikingly similar interpretations of the societal significance of energy and energy-related technologies. For example, concepts of urban metabolism depend on tracing relations of energy-dependence between cities and their hinterlands, or between one part of the world and another. Sankey diagrams, widely used in natural science and in policy, represent energy in much the same way, plotting the relative significance of different sectors (e.g. 
industry and agriculture), and characterising losses and in/efficiencies as energy 'travels' from primary source to end use (Mackay, 2009). Studies of this kind treat energy as if it were a uniform substance, the fate of which can be described and plotted with the help of standardised units, for example, joules, watts, horsepower equivalents etc.

Such techniques underpin other more historical work including that which shows how sources and forms of energy have changed over time. Fouquet and Pearson's review of a thousand years of energy in the UK is organised along these lines (Fouquet and Pearson, 1998), as is Sørensen's still more ambitious 100,000 year input-output based survey of Northern Europe, from Neanderthal society onwards (Sørensen, 2012). Reconstructing the balance-sheets of energy supply and demand historically, or as a means of showing how energy flows between one place and another, gives a sense of the types of fuels and resources involved, and of the efficiency, or otherwise, of their conversion. In the mainstream energy-society literature, calculations like these beg further questions about how the resource bases of societies change and what implications these changes have for social order and upheaval.

The drivers of change

In White's view, processes of organising and converting energy primarily depend on technological innovation this being something that appears to have a trajectory and a momentum of its own (White, 1943). Subsequent discussions of energy-related technology take issue with this representation of progress. For example, Nye's book, Consuming Power (1999) is explicitly positioned as an antidote to analyses like White's in which methods of energy use and conversion figure as independent forces of social and cultural development. Instead, Nye contends that techniques of provision and supply are shaped by social conditions and choices, and that while influenced by forms of technological momentum, energy systems are socially constructed: they 
could be otherwise, and their development is not inevitable. In keeping with this approach, Nye describes some of the interactions involved in bringing new systems into being and reviews the social, geographical and organisational implications of transitions from muscle to water, steam and electrical power. For Nye, as for Verbong and Geels (2010), and Elzen and Geels (2004) understanding energy-related innovation depends on understanding multiple, intersecting social, political and organisational systems (Geels, 2002). As these examples indicate, different authors have very different ideas about what innovation entails but the central problem for Nye, as for White, is essentially one of understanding how technologies of energy provision and supply evolve.

Other commentators place much greater weight on economic systems, arguing that these have a major influence on the directions in which energy systems develop. For example, Fouquet and Pearson conclude that the processes involved in allocating and converting energy are bound both "by a changing growth rate and structure of economic activity' and by the constraints of the 'energetic resources' themselves (Fouquet and Pearson, 1998: 2). Again there are two sides to the coin: whilst the uses of energy are here taken to be outcomes of economic activity, changes in economic activity are sometimes be explained by changes in the 'fuel mix' of society. Bartoletto and del Mar Rubio Varas (2008) make this point with reference to a detailed analysis of energy transitions in Spain and Italy over the last 150 years. They describe transformations in the fuel mix (especially the decreasing significance of wood fuel) and in total energy demand, arguing that 'The use of new energy sources stimulated and, at the same time, came about as a result of, the employing of new technologies, which in their turn had an impact on productivity, the prices of commodities, and their consumption.' (Bartoletto and del Mar Rubio Varas 2008: 62). Whether it is the economy that is thought to drive the energy system or the energy system that is thought to drive the economy, the common contention is that societies are in part defined by the ways in which resources are organised and managed. 
This leads some to conclude that interaction between energy and economic systems is at heart a matter of politics. This is evidently so for those who focus on the distribution of resources (oil, gas etc.) and the vested interests which surround them. Such issues are also important in Harvey and McMeekin's discussion of the potential for switching from higher to lower carbon forms of energy supply. In their view, fuel switching offers capitalist political economies a possible route to sustainable economic growth. However, they suggest that such developments are unlikely without 'scientifically informed, politically-led and long term strategic innovation', regulation and a strong dose of political will (Harvey and McMeekin, 2010: 11).

Whilst the weight given to technological innovation or to political-economic processes varies, the literature referred to this far has the common aim of isolating critical factors and systems that determine, or that are determined by forms and patterns of energy use. From a social-theoretical point of view, such explanatory schemes suppose that social arrangements (and hence forms of energy/use) are best understood as outcomes of the sorts of forces and interactions described above. This commitment remains important, even for those whose project is to demonstrate the interweaving of 'social' and 'technical' considerations and to document the 'social' organisation of technological innovation.

This is not a comprehensive review of all that has been written about energy-society relations, but it is enough to reveal disciplinary differences in how energy and social systems are thought to interact with trajectories of sociotechnical innovation; patterns of urbanisation; divisions of labour; the changing significance of industrial and other sectors, and related forms of state and corporate power. It is also enough to demonstrate the societal importance accorded to energy and resource management.

The implications of change 
In so far as societies depend on energy and its management, radical changes in energy-related technologies or in fuel mix are likely to result in correspondingly massive forms of social upheaval. As one might expect, there are numerous, typically apocalyptic claims about the risks and dangers that lie ahead as resources run out, as populations grow, and as expectations escalate (Urry, 2013). Some of these predictions may well come true. Whether they do so or not, the tendency to suppose that future societies will be subject to dramatic swings, innovative breakthroughs and sweeping transformation is, in a sense, part and parcel of the tendency to conceptualise energy as a generic resource, the need for which is as self-evident as it is taken-for-granted. On this point it is intriguing to compare Urry's view of the impending crises of energy and climate change with White's comments on the scale of societal transformation following the industrial revolution. Urry contends that energy is at the heart of one of the most fundamental contradictions of twentieth-century capitalism. In his words, twentieth century capitalism's

pervasive, mobile and promiscuous commodification involved utterly unprecedented levels of energy production and consumption, a high carbon society whose dark legacy we are beginning to reap. This contradiction could result in a widespread reversal of many of the systems that constitute capitalism as it turns into its own gravedigger. (Urry, 2010: 208)

White, who was writing nearly 70 years before, does not engage with the contradictions of capitalism, or with issues of climate change, but his remarks are alike in underlining the centrality of "the energy situation" for social order.

The Industrial Revolution has run its course, and we are now entering upon the second stage, one of profound institutional change, of social revolution. Barring collapse and chaos, which is of course possible, a new social order will emerge. ...The key to the future, in any event, lies in the energy situation. (White, 1943: 350). 
Both assessments are of their time, but as these extracts indicate, and as the discussion above suggests, the proposition that social systems shape and are shaped by energy systems pervades a vast body of social, political and economic analysis.

In all of this, that nigglingly obvious, but also annoyingly impossible question "what is energy for" slips out of sight. It does so because that question is effectively excluded by a mode of analysis in which social arrangements are taken to be outcomes of various systems of provision, political economy, resource management and technology. To persistently ask "but what is energy for?", and to take that as the central question, is to take a different view of the social. It is to see society not as an outcome of intersecting systems, like geological forces pressing this way and that, but as emergent from, and defined by social practice.

\section{$3 \quad$ Energy and social practices}

We now take what is best described as a practice turn (Schatzki et al., 2001). Theories of practice have a long and varied history in the social sciences, but until very recently there has been little or no attempt to bring this way of thinking about social life and social change to bear on matters of energy. In this section we introduce and explore the relevance and the potential of conceptualising energy not as a cause or a consequence of social systems, but as an ingredient of the social practices and complexes of practice of which societies are composed. As we go on to show, this simple but fundamental change of orientation has significant consequences for those interested in understanding, analysing and influencing energy demand.

Before going further it is important to set out what we take to be useful and relevant features of practice theory. For us, the starting point is the proposition that "social practices ordered across space and time" should feature as "the basic unit of social enquiry" (Giddens, 1984). In taking this approach to heart we differ from those who mobilise practice-based terminology in the energy field, but who do so as a means of revealing differences in people's use of energy whether at home or at 
work (Gram-Hanssen, 2011; Gram-Hanssen, 2010; Hargreaves, 2011). In many such cases, references to practice theory are layered on top of projects and studies that are, in essence, designed to explain patterns of individual or group behaviour. In this context, to talk of practice is to stress the fact that social meanings and norms are shared, or to underline the point that technologies matter and that actions are materially scripted. Despite claiming to adopt a practice perspective, this swathe of energy research does not, in fact, exemplify or depend on a theory of practice - at least not as defined by Giddens or as subsequently developed by Schatzki (2002); or by Shove et. al. (2012). In other words, it does not take social practice as the central topic of enquiry.

If we are to get to grips with the significance of thinking about energy and social practice we need to start from scratch, and we need to do so by working through the energy-related implications of a handful of key ideas that set the practice theories in which we are interested apart from other forms of social theorising.

\section{Energy as an ingredient of social practice}

Theodore Schatzki is one of the key proponents of practice theory (See, for example: Schatzki, 2002, Schatzki, 1996, Schatzki et al., 2001, Schatzki, 2006, Schatzki, 2009, Schatzki, 2010) and in what follows we make use of his work, focusing first on the contention that practices constitute what he calls the "site" of the social, and then on his closely related analysis of materiality, material arrangements and social life.

Before getting into detail, we begin by recognising that energy is used not for its own sake but as part of, and in the course of, accomplishing social practices, examples of which might include cooking, commuting to work, watching TV or conducting meetings (Warde, 2005). Having made this link between energy and practice we suggest that understanding trends and patterns in energy demand (and in provision and supply as well) is in essence a matter of understanding how social practices develop, change and intersect. 
On this point, Schatzki develops a coherent and distinctive explanation of change and order that is rooted in an analysis of practice. In brief, he suggests that accounting for change is not a matter of abstracting sets of forces or systems (e.g. of technology, economics, politics etc.) but of detailing precisely how social practices, and bundles and constellations of practice hang together, and of identifying the material and other arrangements amidst which they 'transpire', and which they also sustain and reproduce.

This is consistent with his representation of practices as the 'site' of the social. To explain, Schatzki takes social practices to be nexuses of saying and doing. He writes about social practices as recognisable blocks or patterns of activity that are filled out and enacted by practitioners, that is, by those who do, and who, in the enactment and performance of these doings reproduce, transform and perpetuate the practices they carry (see also Shove et al. 2012). In his words:

Human coexistence is inherently tied, not just to practices but also to material arrangements. Indeed, social life, as indicated, always transpires as part of a mesh of practices and arrangements: practices are carried on amid and determinative of, while also dependent on and altered by, material arrangements. I call the practice-arrangement nexuses, as inherently part of which human existence transpires, sites of the social.

(Schatzki 2010: 130)

Given that societies are defined by this hanging-together of practice-arrangement bundles, it is appropriate to conclude that social order and change are largely 'established in practices' (Schatzki, 2002: 110). As indicated above, this argues for explanations of social phenomena that are grounded in the 'specifics of pertinent practice-arrangement nexuses and the events that happen to them' (Schatzki, 2010: 146), rather than in generalised claims regarding the impact and influence of abstract systems, be they technological, economic or political. 
Put simply, Schatzki's account of social practice provides us with a way of conceptualising the 'work' (broadly defined to include bundles and constellations of sayings and doings) that goes on within society, and hence of conceptualising and addressing basic questions about what energy is for. More than that, such an account argues for an analysis of energy that starts with and that is inseparable from an analysis of the dynamics of social practice (Shove et al. 2012). From this point of view, understanding energy is first and foremost a matter of understanding the sets of practice that are enacted, reproduced and transformed in any one society, and of understanding how material arrangements, including forms of energy, constitute dimensions of practice.

\section{Material arrangements, energy and social practice}

Practices are not purely social phenomena in that much of social life is intertwined with what Latour refers to as the 'masses', here meaning the huge range of material infrastructures, devices and artefacts that co-constitute and configure so much of what we do (Latour, 1992). Schatzki makes a very similar point, here arguing that 'The arrangements amidst which practices are enacted are not only social: arrangements include substances of all kinds, including natural phenomena along with man-made fabrications' (Schatzki, 2002: 23).

Since 'material arrangements are in some sense crystallisations of matter-energy flows' (Schatzki, 2010: 137) sources of energy - wood, coal, oil, etc., along with technologies of conversion and use (stoves, boilers, cars etc.) qualify as part of such arrangements, but they do so only in relation to specific practices. This is an important observation. Conceptualising energy as, and as part of the material arrangements within which certain practices go on undermines the value and relevance of trying to analyse or characterise energy systems in general. This is because material arrangements including fuels and configurations of matter and energy only have meaning within, and in relation to, the practices in which they are enfolded, and through which they are reproduced. 
Though not inspired by theories of practice as such, Hughes' (1983) classic discussion of emerging networks of power depends on a strikingly similar analysis of the close coupling not only of supply and demand, but of infrastructures and practices. Hughes writes about how electricity systems were built, and about how this depended on deliberate, and quite successful attempts to redefine a range of everyday practices such that electricity became a normal and necessary part of doing things like lighting, cooking and heating. It is plainly obvious that without moves of this kind there would be no 'need' for electricity at all. It is also obvious that people do not consume energy as such: rather patterns of energy consumption depend on a series of historically specific conjunctions of technologies (wiring, light bulbs etc.) and practices (illuminating rooms, reading at night) and constellations of practice, many of which are now disconnected from seasonal variations in daylight.

Turning to another sector, petrol based systems of automobility require the continual, relatively faithful reproduction of an entire complex of variously interdependent practices, ranging from oil exploration through to garage forecourt operation, traffic management and driving itself. If these practices did not 'hang together' in the way they do today, the oil system that is thereby constituted and sustained would, of necessity, take some other form.

Given that the salience, or otherwise of oil, steam or electric power is so thoroughly inseparable from specific bundles and complexes of social practices there is no reason to suppose that energy has any special status as the driver of practice. Likewise, it makes no sense to treat energy and energy-related technologies as the defining features of a series of epoch making transformations, as was the case in White's discussion of energy and the evolution of culture (White, 1943). From this point of view, methods of studying energy in the abstract, for example, by quantifying energy flows in joules or units of horsepower, are just as problematic in that they depend on splitting 'energy' out of the practices in and of which it is a part.

That said, there is some value in making an analytic distinction between material arrangements on the one hand and social practices on the other (Schatzki, 2010). For one thing, this distinction allows 
us to recognise and consider the different temporalities at stake. In everyday life, the enactment of any one practice (for example, cooking a meal or travelling to work) typically depends on the prior existence and availability of a range of energy sources (gas, electricity, oil), infrastructures (grids, pipes, roads) and devices (cookers, cars, bicycles). Schatzki (2006) consequently suggests that whereas practices 'happen' (in the present), material arrangements and infrastructures 'exist', meaning that they endure and persist for longer than any one instance of performance or moment enactment. Second, distinguishing between material arrangements and practices allows us to acknowledge that past and present infrastructures are frequently implicated in the enactment of several practices at once: for example, roads feature as material arrangements amidst which the diverse practices of walking, cycling, driving and horse riding all go on. Third, material arrangements have a forward looking aspect, simultaneously shaping the happening of present practices and hence the configuration both of material arrangements and of practices that do not yet exist but that might do so in the future.

As Schatzki explains:

Material arrangements ubiquitously prefigure practices - that is, the continued happening of the doings and sayings that compose specific practice-by making some actions, inter alia, easier and harder or more direct or circuitous than others. Arrangements also prefigure changes in practices and arrangements. For example, existing coal company arrangements prefigure changes in company operations, making possible changes easier or harder, more or less expensive, more or less time consuming, and so on. Existing material infrastructures in the coal electricity regime also prefigure changes in these infrastructures or in the introduction of new ones (tied to alternative practice-arrangement bundles)

(Schatzki, 2011: 10). 
This is not simply a matter of recognising what Nye and Hughes refer to as 'technological momentum', nor is it only a question of acknowledging the path dependence of complex and distributed infrastructures at the level of power supply, engineering and design. The additional step is to explain that processes of prefiguring only occur and only have effect in and through the trajectories or 'lives' of specific social practices. In other words, whilst there is value in discussing "material arrangements" aside from practice, it is wrong to treat these arrangements as externalised contextual factors that have some sort of independent power of their own. There is, then, a very real sense in which what counts as context itself depends on the specific practices and bundles/constellations of practice that are contextualised, hence Schatzki's conclusion that 'a context has composition, the precise character of which varies with the entities and phenomena that exist in context' (Schatzki, 2002: 63). More straightforwardly, it is vital to remember that material arrangements are themselves made, reproduced and transformed through and as part of happening practices.

Drawing these threads together, understanding energy-society relations depends on understanding the range of practices, material arrangements and social orders in which energy is immersed, and on showing how material arrangements and energy flows are implicated in the constitution and prefiguring of practices and hence of social order/society. From this point of view an account of energy-society relations is, in effect, an account of how 'human transformations of nature, responses to nature and artefact maintenance all transpire as moments of industrial, housing, scientific, informational, medical, and hobby (etc) practices' (Schatzki, 2002: 262).

In contrast to styles of analysis which attribute change to one or more driving forces, or which consider the production and consumption of energy as a generic resource, conceptualising energy as an ingredient of specific social practices provides a means of radically reframing contemporary approaches to energy policy and sustainability. It does so in that it situates energy demand as part 
of, and as in no way separate from the dynamics of social practice. In this it provides a means of reinstating fundamental questions about what energy is for. In the same move, redefining the energy-society agenda in these terms makes it possible - indeed necessary - to mobilise a much wider range of social theoretical resources than is usually the case.

\section{Social theory and energy policy}

Dominant approaches in energy research and policy reproduce resource-based, systems style thinking, emphasising questions that have to do with efficiency of conversion and supply, with the price of fuel or with consumers' views about energy and their attitudes towards consumption and conservation (Parkhill et al., 2013). These strategies of analysis and intervention depend on forcibly disconnecting a discussion of 'energy' from a discussion of social practice: a necessary step if "energy" is to be constituted as a topic in its own right. The problem is that this same move ensures that debates about energy futures routinely proceed without reference to primary questions about what energy is for or about the sets of social practices on which energy demand depends.

\section{Overlooking the dynamics of demand}

One ironic consequence is that whilst government documents like 'Pathways to 2050 ', produced by the UK's Department of Energy and Climate Change (DECC 2010), claim to explore future energy needs and identify ways in which these might be met be met in a suitably low carbon manner, they fail to engage in any meaningful way with the basic dynamics of demand. Instead, the strategy is to take present practices entirely for granted, treating the perpetuation of current "standards" as an unquestioned, non-negotiable part of the equation and focusing exclusively on the efficiency (or otherwise) with which these might be met. In effect the pathways and scenarios that follow address issues of supply, and consider systems of provision, but fail to acknowledge or engage with potentially important changes in the 'work' that is done in society, or in the complex of social 
practices that constitute daily life. Two small examples from this report give a sense of how future needs are conceptualised.

The 'Pathways to 2050' report is organised around a series of scenarios which explore the energy and carbon implications of innovation and change across different sectors. As is usual, the discussion revolves around technologies and resources. For instance, the report sets out a range of possible futures in which the estimated need for hot water varies from a $50 \%$ increase through to a 50\% decrease, compared with 2007 figures. The basic understanding is that hot-water usage is essentially a matter of affordability, taken for granted need and technical efficiency/avoidance of waste. The report consequently supposes that economic growth would result in an "increased use of hot water, and a greater number of hot water using appliances" (Department of Energy and Climate Change, 2010: 99), but makes no reference to what these appliances might be for, or to the social practices of which they might be a part. Meanwhile assessments of the potential for reducing hot water consumption refer to the scope for eliminating waste and promoting efficiency, but not to changes in bathing, laundering or washing, on which hot-water demand actually depends. A $50 \%$ decrease in hot water consumption is therefore "thought to be the limit that could be achieved with greater consumer awareness of hot water efficiency, and more water efficient fittings" (Department of Energy and Climate Change, 2010: 102). This reduction is thought to be feasible because it does not suppose any modification in hot-water using practices or in the demand associated with them.

A second example, this time to do with consumer electronics, demonstrates a similar reluctance to confront the dynamics of demand. Leisure and home entertainment are areas in which practices are co-evolving fast, generating new ways of using electricity and of spending time. Although there has been a six fold increase in consumer electronics since the 1970s (Department of Energy and Climate Change, 2010: 49), the 'Pathways to 2050 ' report makes no attempt to consider or evaluate potential trends in the sector as a whole. Instead, the scenarios focus, exclusively, on whether consumers will, or will not purchase the most efficient electronic devices on the market. The low 
demand scenario, consequently supposes that when 'replacing our consumer electronics and home computing products, we could adopt only the best practice products until 2050' (Department of Energy and Climate Change, 2010: 55).

It is difficult, and perhaps impossible, to predict how practices might change. By setting this issue aside, and by taking present practice as a benchmark the report's authors are, in theory, able to estimate the impact of technological innovation and of improvements in efficiency. Although this makes it possible to produce and compare scenarios, there is no getting away from the fact that the necessary assumption of stability - at the level of practice - is fundamentally flawed. This is not the only route to take. Since the 'Pathways to 2050' report is organised around a series of scenarios there is scope to consider and compare future trajectories in terms of practice. For example, a scenario method could be used to imagine some of the different ways in which consumer-electronicdependent-practices might develop.

We have not singled out the 'Pathways to 2050' report because it is in anyway unusual in failing to engage with the underlying dynamics of demand. Many other policy documents, including the International Energy Agency's 'Saving Energy in a Hurry' (Meier, 2005), updated in 2011 (Pasquier, 2011) proceed on exactly the same basis, comparing and evaluating methods of delivering the same services with fewer resources, and doing so without questioning the characteristics of the practices on which energy use depends.

Although energy is never used outside of some specific context or practice, the discursive strategy of treating it as if it was a meaningful topic in its own right underpins a raft of research and analysis. Across the board, the project of persuading individuals to meet current needs with fewer resources constitutes what seems to be a self-evidently sensible goal that can be safely pursued without fear of stirring up a hornets' nest of uncomfortable questions about the sustainability or otherwise of present constellations of practice. 
On the other hand, it is important to recognise that policies that are designed to deliver similar services but with less energy are anything but "neutral". Like it or not, they play an important part in reproducing the status quo and in sustaining and legitimising contemporary material arrangements and practices. For those interested in long term sustainability, this is a major drawback.

Whilst there is some scope for technological innovation and increased efficiency it is clear that if climate change policy is to make a difference on the scale and at the rate required, it will have to engage more overtly, and more explicitly, with the bundles and constellations of practice on which energy demand depends. By implication any policy analysis that looks decades ahead needs to consider the dynamics of social practice and anticipate changes in what people do and hence in what energy is for. More than that, such analyses need to recognise that some such changes are already set in train and that future possibilities are to some extent prefigured by past and present policy and by the material arrangements and infrastructures associated with them. As mentioned above, designing policies and strategies around the status quo is itself an important intervention in the future dynamics of demand.

\section{Reinstating the dynamics of demand}

Nye's recent book on blackouts (2010) provides a compelling picture of the extent and rate at which energy has become embedded in (and has transformed) what people do. As he explains, in the 1950s, a power cut would affect office work by affecting lighting and ventilation systems. People might have to go home at dusk but typing and filing would continue as normal. Today a power cut would bring much of what constitutes office activity to a sudden halt. This is just one example and Nye is of the view that large parts of the USA would quickly become uninhabitable if power supplies should fail for any length of time. 
The point is not just that societies are increasingly dependent on reliable supplies of electricity and oil in particular. For those interested in developing practice-oriented policy (Shove, 2012) there are two key questions arising from this example: first, how is it that such interconnected bundles and constellations of practices and material arrangements, including technologies of energy provision, distribution and consumption, have taken hold and, second, how might they change? The way to address these questions is not by focusing on how resources are managed and distributed or by discussing the politics and technologies of fuel and power in the abstract. As argued here, these patterns and arrangements are outcomes of what energy is for.

It therefore makes sense to start from this point, from the site of the social, and work back to discover the material arrangements amidst which contemporary practices occur, and which are partly constituted in and through these same practices. This is, in essence, a matter of positioning the practices on which energy demand depends as central topics of policy intervention and of analysis and debate. Whether they are aware of it or not, policy makers of all sorts - not only those who deal with energy - have a hand in prefiguring and sometimes modifying the range of practices that are reproduced in any one society, and the energy demands that follow. Jasanoff and Kim underline the political implications of this conclusion, contending that:

New energy futures will need to reconfigure the physical deep structures of civilization-grids and pipelines, seashores and pastoral landscapes, and suburbs and cities - that were shaped by the energy choices of the past. Equally, we argue here, radical changes in the fuel supply are likely to transform social infrastructures, changing established patterns of life and work and allocating benefits and burdens differently from before. Accordingly analysts should pay greater attention to the social dimensions of energy transitions, complementing more conventional analyses of economic and engineering issues (Jasanoff and Kim, 2013). 
To this we add the very important point that 'social dimensions of energy transitions' only exist, and only have meaning through and as part of the reproduction of specific social practices, hence our persistent emphasis on the need to consider the changing forms of 'work' that material arrangements, including flows of matter and energy enable us to do.

In combination these observations point to a distinctive agenda for future research, some of which will be undertaken by DEMAND, a new RCUK funded Centre focusing on the dynamics of energy, mobility and demand. ${ }^{1}$ The Centre's research programme revolves around three key propositions. First, that energy is used not for its own sake but as part of accomplishing social practices. Energy demand is consequently dynamic, social, cultural, political and historical: it is bound up with the temporal rhythm of society and with what people do. Second, energy demand is profoundly shaped by material arrangements. In a very literal sense demand and the means to consume constitute each other. These means encompass grids, power stations, road and rail networks through to the multitude of devices with which end-users engage (computers, heating systems, cars etc.). Third, these are all implicated in the ongoing reproduction of practice, and of bundles and constellations of practice that define what energy is for. From this it follows that in so far as policy has an impact on energy use, it does so in, through, and by means of modifying or transforming material arrangements, practices and social orders.

These lines of enquiry are rooted in a theoretical approach which takes social practices, including extensive complexes of social practice, ordered across space and time, to be the central unit of analysis. As described above, much existing research including other articles in this special issue, and many policy studies are grounded in different genres of social theory. In many cases, energy supply and demand are conceptualised as outcomes of what are taken to be somewhat independent social, technical, political or economic systems.

As one might expect, different paradigms matter for the way in which questions are framed, and for how energy demand is understood. They also matter for the types of policy intervention proposed 
in response to major challenges, including those of radically reducing $\mathrm{CO}_{2}$ emissions. In this paper we have suggested that in treating energy as a topic in its own right, and in disregarding the extent to which energy demand is embedded in social practice, conventional approaches have the unintended consequence of reproducing contemporary forms of "normal" practice. As such they are incapable of engaging with, let alone debating and promoting change on the scale required. Likewise, in losing sight of basic questions about what energy is for, many social and political theories take the significance of resource management for granted. As a result, the politics and economics of supply are discussed aside from an understanding of the underlying dynamics of demand. In conclusion, we argue for reinstating fundamental questions about what energy is for in research and in policy; we suggest that such a move depends on recognising energy as an ingredient of practice, and we contend that reframing the energy "problem" in these terms is as important for social theory as it is for climate change and sustainability.

\section{Note}

1. DEMAND Centre Award No: EP/K011723/1. For more details, see www.demand.ac.uk

\section{Acknowledgement}

This work was supported by the Engineering and Physical Sciences Research Council (grant number EP/K011723/1) as part of the RCUK Energy Programme and by EDF as part of the R\&D ECLEER Programme.

\section{References}


Allwood, J., Ashby, M., Gutowski, T. and Worrell, E. (2013) 'Material efficiency: providing material services with less material production'. Philisophical Transactions of the Royal Society A 371(1986) doi: $10.1098 /$ rsta.2012.0496

Bartoletto, S. and del Mar Rubio Varas, M. (2008) 'Energy transition and CO2 emissions in Southern Europe: Italy and Spain (1861-2000)'. Global Environment 2: 47-81.

Department of Energy and Climate Change (2010) 2050 Pathway Analysis. London: HMSO.

Elzen, B., Geels, F. W. and Green, K. (eds.) (2004) System innovation and the transition to sustainability : theory, evidence and policy. Cheltenham: Edward Elgar.

Fouquet, R. \& Pearson, P. J. G. (1998) 'A Thousand Years of Energy Use in the United Kingdom'. Energy Journal 19(4): 1-41.

Geels, F. (2002) 'Technological transitions as evolutionary reconfiguration processes: A multi-level perspective and a case-study'. Research Policy 31(8-9): 1257-1274.

Giddens, A. (1994) The Constitution of Society. Cambridge: Polity Press.

Gram-Hanssen, K. (2010) 'Standby consumption in households analysed with a practice theory approach'. Journal of Industrial Ecology 14(1): 150-165.

Gram-Hanssen, K. (2011) 'Understanding change and continuity in residential energy consumption'. Journal of Consumer Culture 11(1): 61-78.

Hargreaves, T. (2011) 'Practice-ing behaviour change: Applying social practice theory to proenvironmental behaviour change.' Journal of Consumer Culture 11(1): 79-99.

Harvey, M. \& Mcmeekin, A. (2010) 'Political Shaping Of Transitions To Biofuels In Europe,Brazil And The USA'. Centre for Research in Economic Sociology and Innovation (CRESI), Working Paper 201002, University of Essex: Colchester.

Hughes, T. (1983) Networks of Power: Electrification in Western Society, 1880-1930. Baltimore MD: John Hopkins University Press. 
Jasanoff, S. and Kim, S.H. (2013) 'Sociotechnical Imaginaries and National Energy Policies'. Science as Culture 22(2): 189-196.

Latour, B. (1992). 'Where are the missing masses? The sociology of a few mundane artefacts' in Bijker, W. and Law, J. (eds.) Shaping Technology/Building Society: Studies in Sociotechnical Change. Cambridge, Mass.: MIT Press.

Mackay, D. J. C. (2009) Sustainable Energy: Without the Hot Air. Cambridge: Uit Cambridge Limited.

Meier, A. (2005) Saving Electricity in a Hurry. Paris: OECD/IEA.

Moellers, N. and Zachmann, K. (2012) Past and Present Energy Societies: How Energy Connects Politics, Technologies and Cultures. New Brunswick: Transaction Pubishers.

Mumford, L. (1967) Technics and human development. New York, N.Y.: Harcourt Brace Jovanovich.

Nye, D. E. (1999) Consuming power: a social history of American energies. Cambridge, Mass: MIT Press.

Nye, D. E. (2010) When the lights went out : a history of blackouts in America. Cambridge, MA: MIT Press.

Parkhill, K., Demski, C., Butler, C., Spence, A. \& Pidgeon, N. (2013) Transforming the UK Energy System: Public Values, Attitudes and Acceptability - Synthesis Report. London: UKERC.

Pasquier, S. (2011) Saving Energy in a Hurry II. Paris: OECD/IEA.

Rosa, E. A., Machlis, G. E. \& Keating, K. M. (1988) 'Energy and Society'. Annual Review of Sociology 14: $149-172$.

Schatzki, T. R. (1996) Social practices : a Wittgensteinian approach to human activity and the social. Cambridge: Cambridge University Press.

Schatzki, T. R. (2002) The site of the social : a philosophical account of the constitution of social life and change. University Park, PA.: Pennsylvania State University Press. 
Schatzki, T.R. (2006) 'On organizations as they happen'. Organization Studies 27(12): 1863-1873.

Schatzki, T.R. (2009) 'Timespace and the Organization of Social Life' in Shove, E, Trentmann, F. and Wilk, R. (eds.) Time, consumption and everyday life. Oxford: Berg.

Schatzki, T. R. (2010) 'Materiality and Social Life'. Nature and Culture 5(2): 123-149.

Schatzki, T.R. (2011) 'Where the Action Is - On Large Social Phenomena Such as Sociotechnical Regimes' Sustainable Practices Research Group Working paper 1. Manchester: University of Manchester.

Schatzki, T. R., Knorr-Cetina, K. and Savigny, E. (eds.) (2001) The practice turn in contemporary theory. London: Routledge.

Shove, E. (2012) 'Putting practice into policy: reconfiguring questions of consumption and climate change'. Contemporary Social Science: 1-15. DOI:10.1080/21582041.2012.692484

Shove, E., Pantzar, M. and Watson, M. (2012) The Dynamics of Social Practice: Everyday Life and How it Changes. London: Sage.

Sørensen, B. (2012) A History of Energy: Northern Europe from the Stone Age to the Present Day. Abingdon: Earthscan.

Urry, J. (2010) 'Consuming the Planet to Excess.' Theory, Culture \& Society 27(2-3): 191-212.

Urry, J. (2013) Societies beyond oil : oil dregs and social futures. London: Zed Books.

Verbong, G. and Loorbach, D. (2012) Governing the Energy Transition: Reality, Illusion Or Necessity? London: Taylor \& Francis.

Verbong, G. P. J. and Geels, F. W. (2010) 'Exploring sustainability transitions in the electricity sector with socio-technical pathways'. Technological Forecasting and Social Change 77(8): 1214-1221.

Warde, A. (2005) 'Consumption and Theories of Practice'. Journal of Consumer Culture 5(2): 131153. 
White, L. A. (1943) 'Energy and the Evolution of Culture'. American Anthropologist 45(3): 335-356. 


\section{Biographical Note}

Elizabeth Shove is Professor in the Department of Sociology, Lancaster University and Co-Director of the DEMAND Centre. She is author/co-author of 9 books, including Sustainable Practice (2013: Routledge) The Dynamics of Social Practice (2012: Sage), and Comfort, Cleanliness and Convenience (2003: Berg).

Gordon Walker is Professor in the Lancaster Environment Centre, Lancaster University and CoDirector of the DEMAND Centre. He has a wide-ranging research profile in energy social science, environmental justice, sustainability and social practice and risk governance. His latest books are Environmental Justice: Concepts, Evidence and Politics (Routledge, 2012) and Energy Justice in a Changing Climate (Zed, 2013). 